\title{
A TRADUÇÃO JURAMENTADA DE DOCUMENTOS ESCOLARES (PORTUGUÊS, FRANCÊS, ALEMÃO)
}

\author{
Tinka Reichmann \\ Adriana Zavaglia
}

\section{Introdução}

Apesar de a tradução de documentos escolares ser muito frequente na prática da tradução juramentada, há poucas publicações acadêmicas ou comerciais a respeito, o que configura uma relação problemática entre a teoria, a prática e o mundo editorial ${ }^{1}$. Essa lacuna é sentida pelos tradutores que lidam com esse tipo de texto cotidianamente, já que os sistemas de ensino são arraigados na legislação e, por isso, são particularmente marcados do ponto de vista cultural.

Sob o aspecto jurídico, a legislação oferece o quadro geral para os sistemas de ensino, com a possibilidade de diversidade por deliberações de ministérios, secretarias ou conselhos de educação, o que abre espaço, por exemplo, para a criação de escolas baseadas em propostas pedagógicas diferenciadas (escolas confessionais, profissionalizantes etc.). Porém, o setor do ensino está sujeito a constantes reformas promovidas por demandas de diferentes setores da sociedade e, parcialmente, por pressões internacionais, como as avaliações realizadas por instituições multilaterais, como o Programa Internacional de Avaliação de Estudantes - PISA.

Do ponto de vista tradutório, há alguns trabalhos a respeito. Podemos citar Stolze (2014), que compara o sistema de notas e de ensino alemão com o estadunidense, britânico, francês e italiano em modelos autênticos (p.111-139 e p.141-168), além de Pilar (2001), que propõe exercícios de tradução, para o espanhol, de certificados acadêmicos alemães autênticos (p.39-54). Há igualmente extensa bibliografia sobre o discurso jurídico em francês e outras línguas, que incide também sobre os documentos escolares ${ }^{2}$ e alguns trabalhos brasileiros, como o de Zavaglia \& Poppi (2010). Mas a questão ainda requer muita reflexão e pesquisa. Delvizio, Barros \& Aubert (2010), por exemplo, discorrem sobre a tradução de termos culturalmente marcados em documentos acadêmicos (português/inglês). Nesse texto, afirmam que a tradução das terminologias constitui um dos principais desafios nessa área (p. 230). No

\footnotetext{
${ }^{1}$ Um dos trabalhos a respeito é o de Delvizio (2011).

${ }^{2}$ Cf. http://www.cttj.ca/Documents/Monographiesetarticlessurlajurilinguistiquefr.pdf
} 
REICHMAN \& ZAVAGLIA - A tradução juramentada de documentos escolares...

entanto, a nossa prática mostra que as dificuldades vão muito além da unidade lexical. Ressaltamos, portanto, a importância de recorrer à maior variedade possível de modelos autênticos para estudar, ensinar, pesquisar e realizar profissionalmente a tradução de documentos escolares, assunto que merece especial atenção.

Considerando essa problemática, este artigo tem como proposta comentar as bases legais dos sistemas de ensino brasileiro, alemão e francês, discutindo-os em termos gerais, com algumas ponderações específicas. Em seguida, levantaremos aspectos contrastivos relacionados, apontando para algumas dificuldades de tradução decorrentes das diferenças de gênero textual e de terminologia e, consequentemente, das especificidades da tradução desses documentos, dando especial atenção aos históricos escolares.

\section{Bases legais dos níveis de ensino brasileiro, francês e alemão}

\subsection{Brasil}

No Brasil, os níveis de ensino são determinados pela Lei de Diretrizes e Bases da Educação Nacional (LDB - Lei n 9394/96), como segue (Ferrarezi Jr., 2011):

\begin{tabular}{|c|c|}
\hline \multicolumn{2}{|c|}{ Educação Básica (art. 21) } \\
\hline Educação Infantil (art. 30) & $\begin{array}{l}\text { Creches e pré-escolas, crianças antes da idade } \\
\text { escolar padrão }\end{array}$ \\
\hline Ensino Fundamental (art. 32) & 9 anos escolares \\
\hline Ensino Médio (art. 35) & $\begin{array}{l}\text { Duração mínima de } 3 \text { anos; pode ser } \\
\text { profissionalizante ou propedêutico (finalidade de } \\
\text { preparar para concursos vestibulares) }\end{array}$ \\
\hline \multicolumn{2}{|c|}{ Educação Superior (art. 44) } \\
\hline Graduação & $\begin{array}{l}\text { Primeira etapa do ensino superior, com duração } \\
\text { variada. Graus de bacharel (formação técnica), } \\
\text { licenciado (formação pedagógica) ou ambos }\end{array}$ \\
\hline Pós-Graduação lato sensu & $\begin{array}{l}\text { Aperfeiçoamento (mínimo de } 180 \text { horas) e } \\
\text { Especialização (mínimo de } 360 \text { horas), sem grau, } \\
\text { ambos apenas com certificado de conclusão do } \\
\text { curso }\end{array}$ \\
\hline Pós-Graduação stricto sensu & $\begin{array}{l}\text { Mestrado (de } 1,5 \text { a } 3 \text { anos), grau e diploma de } \\
\text { Mestre, com defesa pública de dissertação de } \\
\text { mestrado, e Doutorado (de } 2 \text { a } 4 \text { anos), grau e } \\
\text { diploma de Doutor, com defesa pública de tese } \\
\text { de doutorado }\end{array}$ \\
\hline
\end{tabular}

Dado que o sistema escolar brasileiro e suas respectivas bases legais estão descritos de forma detalhada em Delvizio (2011, p.60-64) e em Ferrarezi Jr. (2011, p.13-17), prescindimos de uma descrição mais circunstanciada dos níveis de ensino. Cabe ressaltar, entretanto, que a 
REICHMAN \& ZAVAGLIA - A tradução juramentada de documentos escolares...

base legal do sistema de ensino brasileiro é uma lei federal, como apontado anteriormente, o que o torna centralizado, paralelo ao sistema francês e oposto ao alemão, mais descentralizado. Centralizado ou não, os documentos expedidos por cada estabelecimento escolar podem variar e, de fato, variam.

Antes de passar aos sistemas dos outros dois países, vale notar que os níveis de ensino brasileiros sofreram uma mudança recente que incidiu sobre os primeiros anos escolares ${ }^{3}$. A alteração incluiu o último ano do antigo pré-primário no primeiro bloco da formação, que passou a ser composto por cinco anos e designado de Ensino Fundamental 1, com o $1^{\circ}$ ano (último ano do antigo pré-primário), o $2^{\circ}$ ano (antiga $1^{\mathrm{a}}$ série), $3^{\mathrm{o}}$ ano $\left(2^{\mathrm{a}}\right.$ série), $4^{\mathrm{o}}$ ano ( $3^{\mathrm{a}}$ série) e $5^{\circ}$ ano ( $4^{\mathrm{a}}$ série). Do ponto de vista social, essa alteração incluiu, no ensino público, as crianças que antes ficavam numa espécie de limbo, sem direito à educação, entre a creche e o primário. Do ponto de vista da internacionalização, essa transformação aproximou os níveis escolares brasileiros aos de outros países; no entanto, ainda restam discrepâncias internacionais relacionadas aos conteúdos e ao direcionamento dos alunos em educação básica, além de haver diferenças no modo de ingresso ao ensino superior e na duração das formações. Para a prática da tradução juramentada, esse tipo de alteração configura uma heterogeneidade diacrônica (Zavaglia 2014, p.47-48), que demanda do tradutor uma atualização constante no âmbito jurídico. No caso de singularidades ou de ausência de correspondências contextuais, é possível fazer uso de estratégias tradutórias, como a equivalência difusa ou a assíncrona (p.48), que apontem para a diversidade cultural decorrente das diferenças nas legislações de cada país, como veremos adiante (cf. seções 3 e 4 deste artigo) ${ }^{4}$.

\subsection{França}

Na França, o Ministère de l'éducation nationale (Ministério da Educação Nacional) e o Ministère de l'enseignement supérieur et de la recherche (Ministério do Ensino Superior e da Pesquisa) organizam e administram o ensino no país. Essa centralização resulta em homogeneidade no ensino obrigatório, dos 6 aos 16 anos. Para o ensino fundamental francês, por exemplo, o socle commun de connaissances et de compétences, paralelo ao nosso tronco comum de conhecimentos, propõe sete competências a serem adquiridas pelo aluno: o

\footnotetext{
${ }^{3}$ Lei $\mathrm{n}^{\circ} 11.274$, de 06/02/2006, dispondo sobre a duração de 9 (nove) anos para o ensino fundamental, com matrícula obrigatória a partir dos 6 (seis) anos de idade.

${ }^{4}$ Note-se que, neste caso, trata-se de equivalências tradutórias decorrentes das estratégias de tradução por parte do tradutor e não de equivalência de estudos ou revalidação cuja responsabilidade é das Secretarias Estaduais de Educação.
} 
REICHMAN \& ZAVAGLIA - A tradução juramentada de documentos escolares...

domínio da língua francesa, a prática de uma língua estrangeira, os principais elementos de matemática, a cultura científica e tecnológica, o domínio das técnicas usuais da informação e da comunicação, a cultura humanista e as competências sociais e cívicas. No ensino médio, essa base comum designa-se enseignements communs (ensinos comuns ao pé da letra, paralelos a conhecimentos comuns) e se alarga para outras disciplinas. Porém, há uma descentralização de responsabilidades: os municípios encarregam-se das écoles maternelles e élémentaires (escolas maternais e elementares ao pé da letra, paralelas à nossa pré-escola e ensino fundamental 1), os departamentos ocupam-se dos collèges (colégios ao pé da letra, paralelos ao ensino fundamental 2) e as regiões responsabilizam-se pelos lycées (liceus ao pé da letra, paralelos ao ensino médio) e pelo ensino técnico e profissionalizante.

Os textos legais relacionados à educação nacional francesa podem ser encontrados em quatro grandes referências: o Bulletin Officiel de l'éducation nationale (Boletim Oficial da Educação Nacional), o Journal officiel (Diário Oficial), o Code de l'éducation (Código da Educação) e o Journal officiel de l'Union européenne (Diário Oficial da União Europeia). O Código da Educação agrupa a legislação em questão, regulando seus fatos e atos. Com força de lei, foi publicado no Diário Oficial francês em junho de 2000. Sua base legislativa compõese de nove livros e a regulamentar, de três.

Dessas disposições, derivam as estruturas do ensino na França dos primeiros anos da escola até o ensino superior. Seguem os níveis de ensino francês, que serão comentados adiante: ${ }^{5}$

\begin{tabular}{|c|c|}
\hline \multicolumn{2}{|c|}{ Premier degré: école maternelle et élémentaire (desde 2006, antes era chamada de primaire) } \\
\hline Cycle 1 & $\begin{array}{l}\text { apprentissages premiers - toute petite, petite, } \\
\text { moyenne et grande sections: école maternelle }\end{array}$ \\
\hline Cycle 2 & 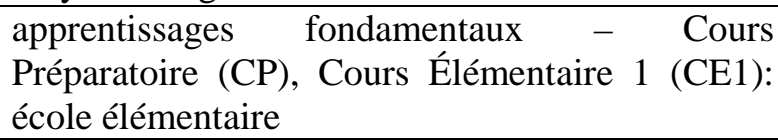 \\
\hline Cycle 3 & $\begin{array}{l}\text { approfondissements }- \text { Cours Élémentaire } 2 \\
\text { (CE2), Cours Moyen } 1(\mathrm{CM} 1) \text { et Cours Moyen } 2 \\
(\mathrm{CM} 2) \text { : école élémentaire. }\end{array}$ \\
\hline \multicolumn{2}{|c|}{ Second degré: école secondaire } \\
\hline \multicolumn{2}{|l|}{ Collège } \\
\hline Cycle d'adaptation & Classe de Sixième \\
\hline Cycle central & Classe de Cinquième et de Quatrième \\
\hline Cycle d'orientation & Classe de Troisième \\
\hline \multicolumn{2}{|l|}{ Lycée } \\
\hline & Classe de Seconde \\
\hline & $\begin{array}{l}\text { Classe de Première (choix entre section littéraire, } \\
\text { scientifique, économique et sociale) }\end{array}$ \\
\hline
\end{tabular}

\footnotetext{
${ }^{5}$ Informações extraídas do seguinte site: http://www.education.gouv.fr/
} 
REICHMAN \& ZAVAGLIA - A tradução juramentada de documentos escolares...

\begin{tabular}{|c|c|}
\hline & Classe de Terminale \\
\hline \multicolumn{2}{|c|}{ Enseignement Supérieur ou Études Supérieures (Admission: Baccalauréat) } \\
\hline Premier Cycle & Licence - Bac+3 (Réforme LMD-2003) \\
\hline Deuxième Cycle & $\begin{array}{l}\text { Master 1, Master } 2 \text { - Bac+5 (Réforme LMD- } \\
\text { 2003) }\end{array}$ \\
\hline Troisième Cycle & Doctorat - Bac+8 (Réforme LMD-2006) \\
\hline
\end{tabular}

\subsection{Alemanha}

Diferentemente da França, a legislação, a organização e a administração do ensino na Alemanha são essencialmente descentralizadas por estarem sujeitas à competência prioritária dos estados federados. A Constituição alemã (Grundgesetz - Lei Fundamental) ${ }^{6}$ de 1949 prevê uma organização federativa das áreas do ensino, da pesquisa e da cultura, e cada estado é responsável por sua política cultural e educativa, contemplando suas especificidades históricas, geográficas, culturais e político-sociais (KMK 2012, p.16). Como os estados que compunham a ex-República Democrática Alemã aderiram à Lei Fundamental pelo tratado de reunificação da Alemanha em 1990, desde então a descentralização das três áreas mencionadas vale para todos os 16 estados federados alemães (p.11). Além disso, todo o sistema escolar alemão está submetido à fiscalização do Estado (p.24).

Apesar do princípio de descentralização e autonomia dos estados federados, há uma necessidade prática de criar estruturas comuns e comparáveis nos sistemas de ensino estaduais a fim de facilitar a mudança de famílias dentro do país. Para coordenar e articular as políticas concernentes, já em 1948 foi criada a Ständige Konferenz der Kultusminister ou Kultusministerkonferenz - KMK (Conferência Permanente dos Secretários de Educação), que é, até hoje, a entidade principal para a organização do sistema de ensino escolar, superior, pesquisa e assuntos culturais na Alemanha ${ }^{7}$. Outra atribuição importante da KMK é o reconhecimento de documentos escolares, diplomas e graus acadêmicos estrangeiros. Para tanto, disponibiliza um site com uma base de dados com informações sobre instituições de ensino e certificados de conclusão de ensino estrangeiros (escola e ensino superior) ${ }^{8}$.

Em nível federal, os principais ministérios competentes por questões de educação e ensino são o Bundesministerium für Bildung, Wissenschaft, Forschung und Technologie BMBF (Ministério Federal do Planejamento Educacional, da Ciência, Pesquisa e Tecnologia)

\footnotetext{
${ }^{6} \mathrm{O}$ teor dessa Lei Fundamental está disponível em língua portuguesa na íntegra no site da Embaixada da Alemanha: http://www.brasil.diplo.de/contentblob/3160404/Daten/1330556/Gundgesetz_pt.pdf

${ }^{7}$ A legislação estadual sobre o ensino escolar e superior da Alemanha está disponível no site da KMK: http://www.kmk.org/dokumentation/rechtsvorschriften.html

${ }^{8}$ http://anabin.kmk.org
} 
REICHMAN \& ZAVAGLIA - A tradução juramentada de documentos escolares...

e o Bundesministerium für Familie, Senioren, Frauen und Jugend - BMFSFJ (Ministério Federal da Família, Terceira Idade, Mulher e Juventude) (KMK 2012, p.39). Apesar da descentralização, o sistema de ensino da Alemanha está dividido, em termos gerais, nas seguintes áreas: Elementarbereich (elementar) para crianças na idade de alguns meses até os seis anos (aproximadamente), Primarbereich (primária) para crianças a partir de seis anos (aproximadamente), Sekundarbereich (secundária), para crianças a partir dos 10 anos (aproximadamente), Tertiärer Bereich (terciária), que corresponde ao ensino superior e a Weiterbildung (formação continuada).

A duração do ensino obrigatório varia de nove a dez anos, dependendo do estado federado, para todas as crianças a partir dos seis anos. O nível primário é formado pelo $1^{\circ}$ ao $4^{\circ}$ ano (em Berlim e Brandemburgo $1^{\circ}$ ao $6^{\circ}$ ano), chamado de Grundschule. Há um momento de transição problemático entre o nível primário e a primeira etapa do nível secundário, dado que as crianças são encaminhadas a, basicamente, três tipos de escola: Hauptschule ( $5^{\circ}$ ao $9^{\circ}$ ano), que corresponde, na maioria dos casos, ao período de ensino obrigatório, Realschule ( $5^{\circ}$ ao $10^{\circ}$ ano), que oferece o certificado de conclusão de nível intermediário e o Gymnasium ( $5^{\circ}$ ao $12^{\circ} / 13^{\circ}$ ano), que é concluído com o Hochschulreife ou Abitur, o certificado de aptidão ou "maturidade" para o ensino superior. Há ainda as escolas integradas (Gesamtschule) que englobam os três tipos de escola. Basicamente, somente alunos do terceiro tipo de escola, Gymnasium, podem cursar o ensino superior, apesar de haver algumas outras possibilidades para ingresso nas escolas superiores técnicas ${ }^{9}$. Segue a tabela sinóptica simplificada:

\begin{tabular}{|c|c|c|c|}
\hline \multicolumn{4}{|c|}{ Elementarbereich } \\
\hline & \multicolumn{3}{|l|}{ Kindertagesstätte } \\
\hline \multicolumn{4}{|c|}{ Primarbereich } \\
\hline \multirow[t]{4}{*}{ Grundschule } & \multicolumn{3}{|c|}{ Jahrgangsstufe 1 (1. Schuljahr) } \\
\hline & \multicolumn{3}{|c|}{ Jahrgangsstufe 2 (2. Schuljahr) } \\
\hline & \multicolumn{3}{|c|}{ Jahrgangsstufe 3 (3. Schuljahr) } \\
\hline & \multicolumn{3}{|c|}{ Jahrgangsstufe 4 (4. Schuljahr) } \\
\hline \multicolumn{4}{|c|}{ Sekundarbereich } \\
\hline & Hauptschule & Realschule & Gymnasium \\
\hline \multirow[t]{7}{*}{ Sekundarbereich I } & Jahrgangsstufe 5 & Jahrgangsstufe 5 & Jahrgangsstufe 5 \\
\hline & Jahrgangsstufe 6 & Jahrgangsstufe 6 & Jahrgangsstufe 6 \\
\hline & Jahrgangsstufe 7 & Jahrgangsstufe 7 & Jahrgangsstufe 7 \\
\hline & Jahrgangsstufe 8 & Jahrgangsstufe 8 & Jahrgangsstufe 8 \\
\hline & Jahrgangsstufe 9 & Jahrgangsstufe 9 & Jahrgangsstufe 9 \\
\hline & & Jahrgangsstufe 10 & Jahrgangsstufe 10 \\
\hline & & & \\
\hline
\end{tabular}

\footnotetext{
${ }^{9}$ Para mais detalhes sobre o sistema de ensino alemão em língua alemã ou inglesa, cf. http://www.kmk.org/
} 
REICHMAN \& ZAVAGLIA - A tradução juramentada de documentos escolares...

\begin{tabular}{|c|c|c|l|}
\hline & - & - & Gymnasium \\
\hline Sekundarbereich II & - & - & Jahrgangsstufe 11 \\
\hline & - & - & Jahrgangsstufe 12 \\
\hline & - & - & (Jahrgangsstufe 13) \\
\hline & \multicolumn{2}{|l|}{} \\
\hline Tertitärer Bereich & \multicolumn{2}{|l|}{ Medizin, Jura, Lehramt } \\
\hline & Bachelor & \multicolumn{2}{l|}{} \\
\hline & Master & \multicolumn{2}{l|}{ staatliche Prüfung/ Staatsexamen } \\
\hline & Promotion & Promotion \\
\hline
\end{tabular}

\section{Comparação dos sistemas}

Os quadros dos sistemas apresentados decorrem das legislações de cada país e dão origem a gêneros textuais singulares e a terminologias específicas. Para levar a cabo uma comparação entre os sistemas dos três países, consideramos primeiramente os conhecimentos e a idade dos alunos em cada nível. Mesmo que os sistemas de que fazem parte sejam distintos, é possível equivalê-los difusamente (Zavaglia 2014, p.42). As equivalências são difusas pelo fato de cada conceito a que remete cada termo ser específico de cada país. Desse modo, aparentemente, o conceito a que remete primeiro ano seria o mesmo de Cours Préparatoire - CP ou 1. Schuljahr; mas não ocorre assim, uma vez que esses marcadores culturais representam marcas culturais específicas, não transponíveis pelas línguas ou pela tradução. De todo modo, é possível, na tradução juramentada de um histórico escolar cuja finalidade seja comprovar, no país de destino, que o titular do documento concluiu aquele ano de estudos específico, traduzir primeiro ano por $C P$ ou por 1 . Schuljahr e vice-versa.

Por outro lado, o Ensino Fundamental brasileiro, dividido em Fundamental 1, com cinco anos de estudo, e Fundamental 2, com quatro anos de estudo, não coincide com o Premier degré (Primeiro grau) francês, que comporta três ou quatro anos de estudo da escola maternal, não obrigatória (crianças a partir de 2 anos), acrescidos de cinco anos da escola elementar (crianças a partir de 6 anos). Tampouco com o Primarbereich alemão, constituído de apenas quatro anos (crianças a partir de 6 anos) ou seis anos em Berlim e Brandemburgo. O nosso Fundamental também não coincide nem com o Second degré (Segundo grau) francês, que abrange o Collège (Colégio), com duração de quatro anos, e o Lycée (Liceu), com três anos, nem com o Sekundarbereich (Secundário) alemão, com até seis anos de duração no primeiro bloco, Sekundarbereich I: Hauptschule, Realschule ou Gymnasium, dependendo da orientação formativa posterior do aluno, e até três no segundo, Sekundarbereich II: Gymnasium. Desse modo, um certificado de conclusão de qualquer um desses níveis a ser traduzido em qualquer direção linguística (por exemplo, do português para o francês ou para o 
REICHMAN \& ZAVAGLIA - A tradução juramentada de documentos escolares...

alemão, seja do Ensino Fundamental 1 e 2, somente do Fundamental 1 ou 2 ou apenas do Ensino Médio) demandará do tradutor juramentado o uso de estratégias diversificadas que deem conta dessas discrepâncias.

Devido à Reforma de Bolonha, a maioria dos cursos superiores franceses e alemães foram adaptados ao sistema Bachelor/Master ${ }^{10}$, o que gera um problema de tradução relacionado aos cursos superiores brasileiros de bacharelado e mestrado (graduação e pósgraduação, respectivamente). A semelhança linguística sugere uma equiparação ou, até mesmo, equivalência errônea entre bacharelado/Bachelor e mestrado/Master. Na tradução juramentada convém ressaltar que a duração dos cursos de bacharelado e Bachelor é bastante distinta (em média 4 a 5 anos e 2 a 3, respectivamente). A duração dos cursos de mestrado e Master já se assemelham mais (em média 2 a 3 anos), entretanto, a dissertação de mestrado geralmente é muito mais extensa que o trabalho de conclusão do Master. Por tal motivo, os procedimentos de Equivalência do Título (válido como pré-requisito para inscrição em cursos de uma determinada instituição de ensino superior) e Reconhecimento de Diploma (válido em todo o território nacional) são decididos caso a caso pela entidade em questão ${ }^{11}$. Cabe, portanto, ao tradutor explicitar tais diferenças, por exemplo, mantendo a nomenclatura original por empréstimo acrescido de explicitação.

\section{Gêneros textuais e especificidades}

Na comparação anterior há relações explícitas ou implícitas, que aqui denominamos marcas culturais, nas quais se entremeiam marcadores culturais. Entendemos aqui as marcas culturais como relações abstratas que se estabelecem espaço-temporalmente entre esquemas culturais mais gerais e esquemas culturais mais específicos, como a relação entre a legislação brasileira sobre o ensino e os sistemas de ensino brasileiro, e os marcadores culturais como objetos textuais que representam essas relações, como o gênero textual brasileiro histórico escolar ou a terminologia desse gênero. Fix (2006) já apontava para essas questões, principalmente ao afirmar que "a própria existência de gêneros textuais é uma manifestação cultural" (p.260) ${ }^{12}$ e que eles "são fenômenos prototípicos e modelares que oferecem

\footnotetext{
${ }^{10} \mathrm{Na}$ França, o bachelor é comumente designado licence, o que também traz confusão com relação à licenciatura brasileira.

${ }^{11} \mathrm{Cf}$. informações nos sites das respectivas instituições de ensino superior ou das suas unidades, p. ex. http://www.usp.br/secretaria/?p=1949 (USP) e http://pos.fflch.usp.br/node/13261 (USP/FFLCH)

12 "Bereits die Tatsache, dass Textsorten existieren (...), ist ein kulturelles Phänomen."
} 
REICHMAN \& ZAVAGLIA - A tradução juramentada de documentos escolares...

orientação para a produção e a compreensão de textos" (p.261) ${ }^{13}$. Logo, produzir um texto significa supor a sua recepção e, por consequência, a sua compreensão, ou seja, presumir que seja possível compartilhá-lo em comunidade (no nosso caso, entre estabelecimentos de ensino de dois ou mais países), mesmo que aspectos subjetivos estejam aí incluídos (particularidades de um dado estabelecimento escolar de um dos países ou singularidades idioletais de um tradutor).

Com respeito à área escolar, os textos relacionados são diversos, tanto com relação à sua natureza quanto à tipologia e aos gêneros, devido à sua inserção no respectivo sistema nacional de ensino. Muitos documentos são expedidos pelas escolas e universidades, como atas (de conselhos ou reuniões), certidões, requerimentos e convocações, declarações e, entre outros, editais. No Brasil, podemos citar, por exemplo, os atos oficiais que recobrem questões relacionadas ao estabelecimento (como autorização de funcionamento, credenciamento de cursos, processo de estadualização ou municipalização etc.) e os atos internos (proposta pedagógica, plano de curso, regimento escolar, matrícula etc.). Esses atos oficiais em relação com os estabelecimentos escolares - o que configura uma marca cultural - dão origem a diferentes marcadores culturais, documentos de diferentes tipos que pertencem a gêneros distintos e possuem terminologias diversas. Pela nossa prática, os históricos escolares são um dos gêneros textuais mais consolidados no contexto da tradução juramentada, além dos diplomas e certificados de conclusão, cujos modelos e formulários são baseados atualmente na Lei $n^{\circ}$ 9394/96 $6^{14}$; por esse motivo, demos a eles mais atenção neste trabalho.

Devido à diversidade das instituições de ensino, mesmo em sistemas mais centralizados, a principal função do tradutor não é encontrar um equivalente pleno, que muitas vezes não existe, mas encontrar técnicas para, por um lado, preservar o referente cultural e, ao mesmo tempo, torná-lo compreensível no texto traduzido (cf. Delvizio, 2011 p. 281). Consiste aí uma das dificuldades do trabalho do tradutor juramentado (como, por exemplo, na tradução de abreviações, notas e menções, títulos de disciplinas, entidades institucionais, entre outros), que precisa evitar adaptações, pela própria natureza do texto que traduz, diversificando suas estratégias, entre transcrições, empréstimos, modulações, traduções intersemióticas, explicitações e até mesmo implicitações ou omissões (cf. modalidades tradutórias de Aubert, 1998).

\footnotetext{
13 "Textsorten sind musterhafte, prototypische Phänomene und bieten so Orientierung sowohl für das Textherstellen als auch für das Textverstehen."

${ }^{14}$ Informações extraídas de http://www.nre.seed.pr.gov.br/toledo/arquivos/File/manual_do_secretario.pdf.
} 
REICHMAN \& ZAVAGLIA - A tradução juramentada de documentos escolares...

Por tal motivo, é frequente incluir explicitações ou paráfrases entre parêntesis ou em notas de rodapé precedidas de "N.d.T." (Nota do Tradutor). A título de exemplo, recentemente a tradução de um certificado escolar de um Berufskolleg für Grafikdesign (colégio profissional privado com cursos de três anos de duração) da Alemanha recebeu a seguinte nota: "certificado de conclusão de escola secundária profissionalizante com habilitação em desenho gráfico e com aptidão para ingressar na Fachhochschule (Escola Superior Técnica)". Os termos baccalauréat do francês e vestibular do português brasileiro, embora remetam a uma mesma função pragmática geral, a de ingressar no ensino superior após a conclusão do ensino médio, só são equivalentes assincronamente, ou seja, pedem por um empréstimo seguido de explicitação por nota.

Num estudo sobre históricos escolares acadêmicos alemães e brasileiros, Reichmann (2013) constatou a grande diversidade na nomenclatura deste gênero textual no sistema alemão em oposição ao sistema brasileiro, que usa "histórico escolar" em todo o território nacional. Portanto, na Alemanha há termos concorrentes para denominar este documento escolar, como: Bescheinigung über erbrachte Studien- und Prüfungsleistungen, Notenspiegel, Leistungsübersicht, Leistungsbescheinigung, Leistungsnachweis, Transcript of Records, Datenabschrift, entre outros. Tal diversidade terminológica na Alemanha está estreitamente relacionada ao sistema escolar descentralizado em que cada estado ou instituição denomina o documento da maneira considerada mais conveniente, apesar de haver uma tendência à harmonização pela Reforma de Bolonha do uso de "Transcript of Records" e seus equivalentes em outros idiomas.

No caso das notas e menções em históricos escolares, o tradutor não se depara com uma unidade lexical comum, mas com um número ou uma letra que remete a um valor terminológico. No liceu francês, por exemplo, as notas vêm registradas num contexto: após o nome da matéria e do professor, assinalam-se a média do aluno e a da classe, a menor e a maior nota da classe, seguidas de comentários do professor; além disso, faltas e atrasos são registrados abaixo da tabela de notas. Essa disposição de conteúdo e as informações dadas, típicas do gênero textual bulletin francês de liceu, não se verificam num histórico escolar de ensino médio brasileiro. Desse modo, cabe ao tradutor juramentado fazer com que o estabelecimento escolar brasileiro que vai receber a tradução desse documento escolar compreenda-o, por um lado, quanto ao gênero e às terminologias e, por outro, a partir das equivalências instauradas pelo profissional das duas línguas, estabeleça um paralelo entre as marcas e os marcadores culturais dos dois países. Para tanto, o tradutor provavelmente 
REICHMAN \& ZAVAGLIA - A tradução juramentada de documentos escolares...

incluirá notas de rodapé para explicitar as dissonâncias percebidas (no Brasil, por exemplo, as notas são atribuídas sobre 10 e na França, sobre 20) e se acomodará às singularidades dos discursos de cada gênero (os comentários dos professores franceses, por exemplo, vão do registro coloquial ao poético, passando por citações, provérbios e idiomatismos).

\section{Conclusão}

No contexto da globalização, há uma crescente necessidade de reconhecimento de certificados escolares e, portanto, de traduções. Apesar de todos os esforços de padronização dos sistemas de ensino, por exemplo no nível superior na União Europeia pela Reforma de Bolonha, ainda persistem muitas diferenças. Cabe, portanto, ao tradutor público ou juramentado realizar pesquisas aprofundadas não somente sobre os gêneros, abreviações e terminologias em contraste, mas também sobre as especificidades de cada instituição emissora de determinado documento escolar no respectivo sistema de ensino. As constantes reformas nesse contexto, sejam elas em maior ou menor dimensão, representam um desafio específico da tradução juramentada de documentos escolares. A preocupação do tradutor em atualizar seus conhecimentos e aprimorar as técnicas de tradução é fundamental para que a sua tradução possa exercer a função de veicular as marcas e os marcadores culturais de determinado sistema de ensino de maneira compreensível para o receptor da tradução.

\section{Referências}

AUBERT, F. H. Modalidades de tradução: teoria e resultados. Tradterm, São Paulo, v. 5, n. 1, p.99-128, 1998.

DELVIZIO, I. A. Tradução Juramentada de documentos escolares inglês $\rightarrow$ português: questões culturais, terminológicas e tradutórias. 2011. $388 \mathrm{f}$. Tese (Doutorado) - Curso de Estudos Linguísticos, Unesp, S. J. do Rio Preto, 2011. Disponível em: <http://base.repositorio.unesp.br/>. Acesso em: 10 ago. 2014.

DELVIZIO, I. A.; BARROS, L. A.; AUBERT, F. H. Modalidades tradutórias aplicadas à tradução juramentada de documentos acadêmicos. In: BARROS, L. A.; ISQUERO, A. N. (Org.). O léxico em foco: múltiplos olhares. São Paulo: Unesp, 2010. p. 219-232. Disponível em: <http://books.scielo.org>. Acesso em: 10 ago. 2014.

FERRAREZI JR, C. Guia do trabalho científico: do projeto à redação final. São Paulo: Contexto, 2011. 
FIX, U. Was heißt Texte kulturell verstehen? Ein- und Zuordnungsprozesse beim Verstehen von Texten als kulturellen Entitäten. In: BLÜHDORN, H.; BREINDL, E.; WASSNER, U. (Org.). Text - Verstehen: Grammatik und darüber hinaus. Berlin: de Gruyter, 2006. p. 254-276.

KMK (Kultusministerkonferenz), Das Bildungswesen in der Bundesrepublik Deutschland 2011-2012. 2012. Disponível em: <http://www.kmk.org/dokumentation/>. Acesso em: 10 ago. 2014.

KMK (Kultusministerkonferenz), Basic Structure of the Educational System in the Federal Republic of Germany. 2014. Disponível em: <http://www.kmk.org/fileadmin/doc/Dokumentation/Bildungswesen_en_pdfs/en2014.pdf>. Acesso em: 10 ago. 2014.

REICHMANN, T. Die Textsorte Notenspiegel im Hochschulkontext: didaktische Anregungen für den Übersetzungsunterricht deutsch/portugiesisch.. In: FANDRYCH, C. et al. (Org.). Text, Diskurs und Translation im Wandel. Tübingen: Stauffenburg, 2013. p. 101-110.

STOLZE, R. Praxishandbuch Urkundenübersetzung: Fertigkeiten, Terminologie, Rechtssprache. Tübingen: Stauffenburg, 2014.

PILAR, E. La traducción de documentos alemanes: traducción jurada. Granada: Comares, 2001.

ZAVAGLIA, A. Marcas culturais no léxico especializado da tradução juramentada. In: ISQUERO, A. N.; CORNO, G. O. M. As ciências do léxico: lexicologia, lexicografia, terminologia. Campo Grande: Editora da Ufms, 2014. p. 39-48.

ZAVAGLIA, A.; POPPI, C. Aspectos culturais da tradução juramentada. Cadernos de Terminologia, CITRAT, São Paulo, 2012, v. 5, p. 53-83. (Temas de Tradução Juramentada) 